\title{
Analisis Pengendalian Kualitas Line Produksi Body Inner K56 dengan Tahapan DMAIC di PT.KMIL (Kurnia Mustika Indah Lestari)
}

\author{
Helena Sitorus $^{* 1}$, Gunawan Ferdiansyah ${ }^{2}$ \\ Program Studi Teknik Industri, Fakultas Teknik, Universitas Bhayangkara Jakarta Raya \\ e-mail: *11 helena.sitorus@dsn.ubharajaya.ac.id, ${ }^{2}$ gunawanferdiansyah92@gmail.com, \\ * Korespondensi: helena.sitorus@dsn.ubharajaya.ac.id
}

\begin{abstract}
One of the products of PT. Kurnia Mustika Indah Lestari is the inner body of K56. In one month the product rejects amounted to $2.0 \%$, which exceeds the tolerance limit set by the company, namely $0.5 \%$. It is necessary to carry out research aimed at determining the root of the dominant problem that causes rejection of the inner K56 body and determining the quality improvement proposal. The method used is quality control with the DMAIC stage. The results of the research findings show that the dominant root cause of reject burry is that work instructions are not carried out (Method) and working in a hurry to quickly rest (Human). The reject scratch type is due to lack of skill (Method) and pursuing a lot of rest time (Human). The recommendation to improve the quality of the reject burry is to carry out work instructions, be more careful when loading the material into the dies, always clean the inside of the dies, checkman supervises the manpower of the production process so that it works according to cycle time. For the reject scratch type, it is to provide training for man power, give warning instructions for the placement of parts while running the process, set rules for working times that are not too fast, take advantage of spare time to clean the machine.
\end{abstract}

Keywords: Quality, Reject, DMAIC.

\section{ABSTRAK}

Salah satu produk PT. Kurnia Mustika Indah Lestari adalah body inner K56. Dalam satu bulan reject produk sebesar $2,0 \%$ hal ini melebihi batas toleransi yang ditetapkan perusahaan yaitu sebesar $0,5 \%$. Sehingga penelitian ini bertujuan untuk menentukan akar masalah dominan yang menyebabkan reject pada body inner K56 dan menentukan usulan perbaikan kualitas. Metode yang digunakan adalah pengendalian kualitas dengan tahapan DMAIC. Hasil temuan penelitian menunjukan bahwa akar masalah dominan penyebab reject burry adalah instruksi kerja tidak dilaksanakan (Metode) dan bekerja terburu-buru agar cepat istirahat (Manusia). Jenis reject scratch adalah karena kurangnya skill (Metode) dan mengejar waktu istirahat yang banyak (Manusia). Usulan perbaikan kualiatas untuk jenis reject burry adalah menjalankan intruksi kerja, lebih teliti saat memasukan material ke dalam dies, selalu membersihkan bagian dalam dies, checkman mengawasi manpower proses produksi agar bekerja sesuai cycle time. Untuk jenis reject scratch adalah memberikan pelatihan bagi man power, memberikan warning intruksi penempatan part saat menjalankan proses, menetapkan aturan waktu bekerja yang tidak terlalu cepat, memanfaatkan waktu senggang untuk membersihkan mesin.

Kata Kunci : Kualitas, Reject, DMAIC.

\section{PENDAHULUAN}

Pengendalian kualitas merupakan salah satu kunci untuk memenangkan persaingan di dunia industri. Perusahaan dituntut untuk menghasilkan produk dengan tingkat kualitas yang tinggi dan efisien. Pengendalian kualitas yang baik pada proses produksi dilakukan agar dapat mendeteksi dan mengantipasi ketidaknormalan secara cepat. $\begin{array}{rrrr}\text { Six } & \text { sigma merupakan istilah statistik } \\ \text { untuk } & \text { menyatakan seberapa besar }\end{array}$ penyimpangan proses terhadap standar mutu yang sempurna. Six sigma juga disebut sebuah proses yang mengaplika-sikan alat statistik dan teknik reduksi reject dengan tingkat kualitas six sigma menghasilkan 99,99966\% baik atau 3,4 produk reject dari sejuta produk untuk mencapai kepuasan pelanggan. Serta 
Helena Sitorus, Gunawan Ferdiansyah

Submitted: 11/11/2020; Revised: 13/11/2020; Accepted: 13/11/2020; Published: 29/12/2020

mengkonversi nilai six sigma dengan jumlah reject produk per satu juta produksi (defect per million).

Produk yang diteliti yaitu body inner K56 di PT KMIL (Kurnia Mustika Indah Lestari) karena dalam satu periode mengalami tingkat reject produk melebihi batas standar yang ditetapkan oleh perusahaan. Sering terjadi penumpukkan komponen produk yang disebabkan karena kualitas proses di mesin sebelumnya belum sesuai dengan drawing dan SOP yang ditentukan, sehingga di stasiun produksi berikutnya mengalami kekosongan part untuk diproses dan akhirnya menunggu. Hasil produksi Body Inner K56 dapat dilihat pada Tabel 1.

Tujuan dari penelitian ini adalah Menentukan akar masalah dominan yang menyebabkan reject pada body inner K56, Menentukan usulan perbaikan kualitas dalam pembuatan body inner K56 dengan tahapan DMAIC
Tabel 1 Hasil Produksi Body Inner K56

\begin{tabular}{rccc}
\hline Tgl & $\begin{array}{c}\text { Total } \\
\text { Produksi } \\
\text { (unit) }\end{array}$ & $\begin{array}{c}\text { Reject } \\
\text { (Unit) }\end{array}$ & $\begin{array}{c}\text { Presentase } \\
\text { Reject }\end{array}$ \\
\hline 1 & 1500 & 35 & $2,3 \%$ \\
2 & 1485 & 28 & $1,9 \%$ \\
3 & 1475 & 22 & $1,5 \%$ \\
4 & 1455 & 21 & $1,4 \%$ \\
7 & 1500 & 32 & $2,1 \%$ \\
8 & 1500 & 35 & $2,3 \%$ \\
9 & 1475 & 23 & $1,6 \%$ \\
10 & 1485 & 26 & $1,8 \%$ \\
11 & 1455 & 20 & $1,4 \%$ \\
14 & 1500 & 37 & $2,5 \%$ \\
15 & 1485 & 32 & $2,2 \%$ \\
16 & 1500 & 36 & $2,4 \%$ \\
17 & 1475 & 27 & $1,8 \%$ \\
18 & 1455 & 22 & $1,5 \%$ \\
21 & 1495 & 29 & $1,9 \%$ \\
22 & 1500 & 32 & $2,1 \%$ \\
23 & 1500 & 39 & $2,6 \%$ \\
24 & 1485 & 24 & $1,6 \%$ \\
25 & 1455 & 21 & $1,4 \%$ \\
28 & 1500 & 40 & $2,7 \%$ \\
29 & 1500 & 40 & $2,7 \%$ \\
30 & 1485 & 38 & $2,6 \%$ \\
31 & 1495 & 37 & $2,5 \%$ \\
& 34160 & 696 & $2,0 \%$ \\
\hline
\end{tabular}

\section{Pengendalian Kualitas}

Pengendalian kualitas adalah suatu teknik dan aktivitas atau tindakan yang terencana yang dilakukan untuk mencapai, mempertahankan, dan meningkatkan kualitas suatu produk dan jasa agar sesuai dengan standar yang telah ditetapkan dan dapat memenuhi kepuasan konsumen. (Assauri S, 2012)

\section{Metode Six Sigma}

Six sigma didefinisikan sebagai suatu metodologi yang menyediakan alat-alat untuk peningkatan proses bisnis dengan tujuan untuk memperbaiki proses produksi yang difokuskan pada usaha mengurangi variasi proses sekaligus mengurangi cacat, sedemikian sehingga dapat mencapai 3,4 DPMO. Upaya peningkatan target Six Sigma dapat dilakukan menggunakan dua metodologi, yaitu (1) Six 
Helena Sitorus, Gunawan Ferdiansyah

Submitted: 11/11/2020; Revised: 13/11/2020; Accepted: 13/11/2020; Published: 29/12/2020

Sigma - DMAIC (Define, Measure, Analyze, Improve, Control) dan (2) Design for Six Sigma DMADV (Define, Measure, Analyze, Design, Verify). DMAIC digunakan untuk meningkatkan proses bisnis yang telah ada, sedangkan DMADV digunakan untuk menciptakan desain proses baru dengan cara sedemikian rupa agar menghasilkan kinerja bebas kesalahan (Zero Defects). Dalam penelitian ini digunakan tahap DMAIC karena tujuan dalam penelitian ini adalah untuk meningkatkan proses bisnis yang sudah ada sebelumnya. (Muhaemin, 2012).

\section{Analisa Dengan Beberapa Rangkaian Tool}

1. Data Sheet

Dokumen yang berisi ringkasan kinerja dan karakteristik lain dari suatu hasil laporan hasil produksi dan cukup terperinci untuk merancang suatu kegiatan dan penanganan masalah yang terjadi dalam laporan keseluruhan.

2. Diagram SIPOC (Supplier, Input, Process, Output, Customer)

SIPOC adalah suatu alat visual yang digunakan untuk mendokumentasikan proses-proses dari awal hingga akhir dan berfungsi untuk mengidentifikasikan elemen-elemen relevan dari proyek perbaikan yang akan dikerjakan.

3. CTQ (Critical To Quality)

Critical To Quality, Critical artinya penting dan kritis. Quality artinya kualitas atau mutu. Jadi apa yang paling kritis untuk mutu kita dan apa yang pelanggan mau.

4. DPMO (Defects Per Milion Opportunities)

DPMO adalah Defects Per Million Opportunities yaitu reject per satu juta kesempatan. 3,4 DPMO artinya adalah 3.4 reject dalam satu juta kesempatan. DPMO merupakan salah satu dari penilaian kapabilitas proses (Process Capability) untuk mengukur seberapa baiknya suatu proses produksi.

Rumus DPMO dapat dilihat pada persamaan 1

DPMO $=\frac{\text { Total Dafect }}{\text { CTQ } \times \text { in }} x 1.000 .000$
Keterangan:

DPMO = Defects Per Million

Opportunities

$\mathrm{D} \quad=$ Jumlah Defect

$\mathrm{N} \quad=$ Total Produksi

CTQ = Critcal To Quality

5. Sigma Level

Tahap-tahap perhitungan nilai sigma adalah sebagai berikut:

1. Menentukan jumlah unit yang akan diukur

2. Menghitung jumlah reject

3. Menentukan CTQ Potensial

4. Hasil perhitungan DPMO

5. Menghitung nilai kapabilitas sigma

Perhitungan nilai kapabilitas ini digunakan untuk menentukan tingkat sigma. Hasil dari perhitungan kapabilitas sigma, dapat diketahui kemungkinan produk cacat. Penentuan nilai sigma ditentukan dengan rumus:

Nilai Sigma=Nomsinv $\left(\frac{1-\text { DPNO }}{1.000 .000}\right) \times 1,5 \ldots$. (2)

6. Diagram Pareto

Pada konsep pareto, disebutkan bahwa $80 \%$ akibat dihasilkan oleh $20 \%$ penyebab atau bisa juga diterjemahkan dengan $80 \%$ hasil usaha adalah buah dari $20 \%$ usaha yang produktif dan optimal.

7. Control Chart

Control chart adalah suatu alat yang secara grafis digunakan untuk memonitor dan mengevaluasi apakah suatu aktivitas atau proses berada dalam pengendalian kualitas, menjelaskan nilai-nilai statistik dari reject keluaran yang dilengkapi batas atas, garis tengah dan batas bawah.

Berikut rumus peta kedali atau control chart :

1. $\mathrm{CL}=\mathrm{P}=\frac{2 \mathrm{p}}{\mathrm{n}}$

2. $\mathrm{UCL}=\mathrm{P}+3 \sqrt{\frac{p(1-\mathrm{p})^{\mathrm{n}}}{\mathrm{n}}}$

3. $\mathrm{LCL}=\mathrm{P}-3 \sqrt{\frac{p(1-p)}{n}}$

Keterangan:

$\mathrm{P}=$ rata-rata ketidaksesuaian

$\mathrm{np}=$ jumlah produk reject

$\mathrm{n}=$ jumlah produk diamati

$\Sigma \mathrm{n}=$ jumlah total produk reject

8. Cause and Effect Diagram 
Helena Sitorus, Gunawan Ferdiansyah

Submitted: 11/11/2020; Revised: 13/11/2020; Accepted: 13/11/2020; Published: 29/12/2020

Merupakan sebuah gambaran grafis yang menampilkan data mengenai faktor penyebab dari kegagalan atau ketidaksesuaian, hingga menganalisa ke sub paling dalam dari faktor penyebab timbulnya masalah.

9. Brainstorming

Merupakan adalah teknik yang digunakan dalam diskusi kelompok untuk menghasilkan gagasan, pikiran, atau ide yang baru, dan inovativ.

10. Metode Analisa 5W1H

Merupakan metode terdiri atas 6 pertanyaan yang meliputi what, where, when, why, who dan how.

\section{METODE PENELITIAN}

Langkah penelitian yang digunakan pada penelitian ini adalah metode six sigma dengan tahapan DMAIC yaitu:

1. Tahap Define

Pada tahapan ini dilakukan pengumpulan data kuantitatif maupun kualitatif dari perusahaan berupa data sheet, diagram SIPOC, dan CTQ sehingga diketahui jenis-jenis reject produk yang dihasilkan.

2. Tahap Measure

Pada tahap ini dilakukan pengukuran terhadap karakteristik kualitas produk dengan perhitungan DPMO untuk mengetahui sigma level dan diagram peta kendali untuk mennetahui batas atas dan batas bawah dari proses produksi per bulan

3. Tahap Analyze

Pada tahap ini melakukakan analisis terhadap data-data hasil produksi dengan menggunakan diagram pareto, Cause Effect Diagram dan Brainstorming.

4. Tahap Improve

Merupakan tahap peningkatan kualitas dengan melakukan pengukuran hasil dari analisis, dan kemudian menerapkan tindakan perbaikan dengan $5 \mathrm{~W} 1 \mathrm{H}$.

5. Tahap Control

Merupakan tahap peningkatan dan penjagaan kualitas dengan memastikan hasil perbaikan kualiatas dapat dilaksanakan sebagai upaya untuk terus memantau produksi dengan PIC (Person In Charge) yang dapat menjadi acuan untuk terus melakukan perbaikanperbaikan.
Berikut diagram alur dari metode penelitian ini :

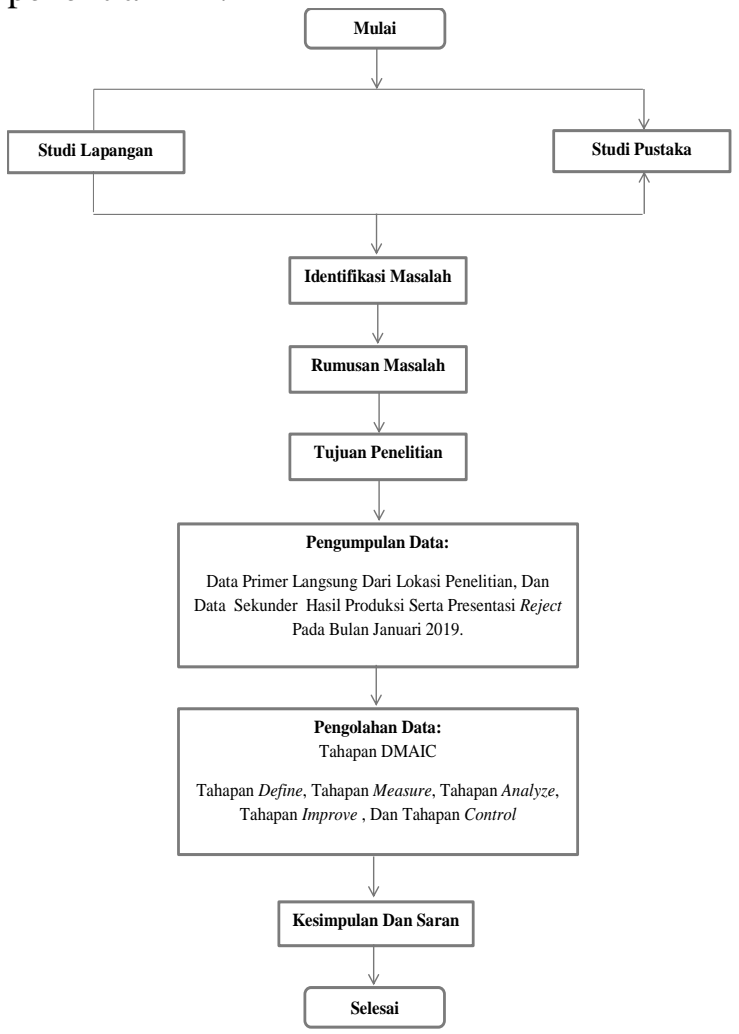

Gambar 1 Kerangka Berpikir

\section{HASIL DAN PEMBAHASAN \\ Tahapan Define}

Empat penyebab di antaranya ada beberapa yang bisa di kategorikan paling dominan dalam meghasilkan produk body inner K56 sebagai berikut:

1. Burry

Reject produk yang disebabkan oleh proses blanking.Dengan tiga kriteria reject yaitu burry tebal, burry halus, dan tepi part tajam.

2. Scratch

Reject produk yang disebabkan oleh proses pembuatan slit. Dengan tiga kriteria reject yaitu bagian luar part scratch, bagian keseluruhan part scratch halus, scratch terlalu dalam di bagian luar part.

3. Penyok

Reject produk yang disebabkan oleh proses rolling karena daya tekan saat dilakukan rolling part. Dengan dua kirteria reject yaitu oval dan jigjag. 
Helena Sitorus, Gunawan Ferdiansyah

Submitted: 11/11/2020; Revised: 13/11/2020; Accepted: 13/11/2020; Published: 29/12/2020

4. Tembus

Reject produk yang disebabkan oleh proses unfication. Dengan dua kriteria yaitu tipis dan tembus.

\section{Data Sheet}

Tabel 2 merupakan data Sheet untuk hasil reject dalam satu bulan

Tabel 2 Data Sheet

\begin{tabular}{|c|c|c|c|c|c|c|}
\hline \multirow{2}{*}{$\operatorname{Tgl}$} & \multirow{2}{*}{ Total Produksi (unit) } & \multicolumn{3}{|c|}{ Reject } & \multirow[b]{2}{*}{ Tembus } & \multirow{2}{*}{ Total } \\
\hline & & Burry & Scratch & Penyok & & \\
\hline 1 & 1500 & 16 & 14 & 3 & 2 & 35 \\
\hline 2 & 1485 & 15 & 11 & 2 & & 28 \\
\hline 3 & 1475 & 10 & 11 & 1 & & 22 \\
\hline 4 & 1455 & 9 & 11 & 1 & & 21 \\
\hline 7 & 1500 & 14 & 16 & 2 & & 32 \\
\hline 8 & 1500 & 16 & 13 & 2 & 4 & 35 \\
\hline 9 & 1475 & 12 & 9 & 1 & 1 & 23 \\
\hline 10 & 1485 & 13 & 12 & 1 & & 26 \\
\hline 11 & 1455 & 11 & 8 & 1 & & 20 \\
\hline 14 & 1500 & 20 & 15 & 2 & & 37 \\
\hline 15 & 1485 & 17 & 14 & 1 & & 32 \\
\hline 16 & 1500 & 15 & 18 & 1 & 2 & 36 \\
\hline 17 & 1475 & 17 & 9 & 1 & & 27 \\
\hline 18 & 1455 & 9 & 12 & 1 & & 22 \\
\hline 21 & 1495 & 13 & 15 & 1 & & 29 \\
\hline 22 & 1500 & 17 & 11 & 2 & 2 & 32 \\
\hline 23 & 1500 & 21 & 17 & 1 & & 39 \\
\hline 24 & 1485 & 10 & 12 & 2 & & 24 \\
\hline 25 & 1455 & 11 & 9 & 1 & & 21 \\
\hline 28 & 1500 & 18 & 17 & 1 & 4 & 40 \\
\hline 29 & 1500 & 21 & 16 & 2 & 1 & 40 \\
\hline 30 & 1485 & 19 & 18 & 1 & & 38 \\
\hline 31 & 1495 & 19 & 17 & 1 & & 37 \\
\hline \multirow[t]{4}{*}{$\Sigma$} & 34160 & 343 & 305 & 32 & 16 & 696 \\
\hline & $\%$ & $49,28 \%$ & $43,82 \%$ & $4,60 \%$ & $2,30 \%$ & $100 \%$ \\
\hline & Total reject & \multicolumn{5}{|c|}{696} \\
\hline & Presentase & & & & & \\
\hline
\end{tabular}

\section{Identifikasi Diagram SIPOC}

Diagram SIPOC pada penelitian ini dapat dilihat pada Gambar 2 
Helena Sitorus, Gunawan Ferdiansyah

Submitted: 11/11/2020; Revised: 13/11/2020; Accepted: 13/11/2020; Published: 29/12/2020

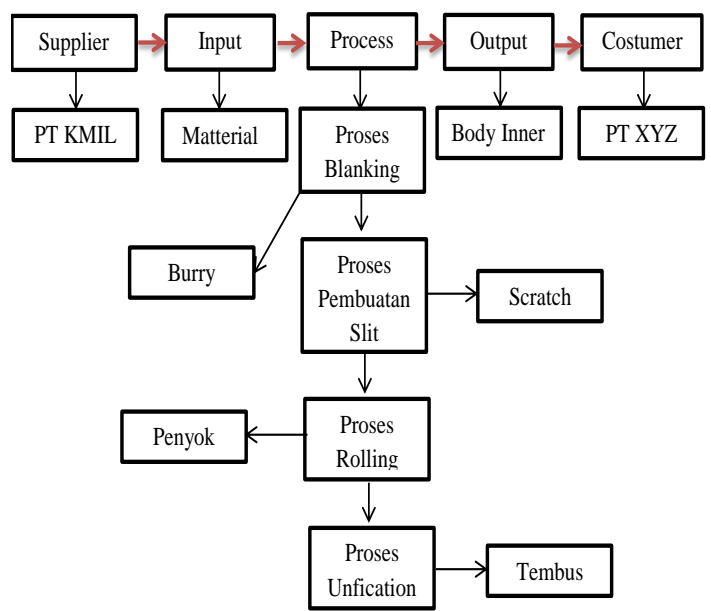

Gambar 2 Diagram SIPOC

CTQ (Critical To Quality) K56

CTQ dari proses pembuatan body inner

\begin{tabular}{|c|c|c|c|}
\hline Proses & $\begin{array}{c}\text { Karakteristik } \\
\text { Kualitas }\end{array}$ & $\begin{array}{l}\text { Kriteria } \\
\text { Reject }\end{array}$ & $\begin{array}{l}\text { CTQ } \\
\text { Poten } \\
\text { sial } \\
\end{array}$ \\
\hline $\begin{array}{l}\text { Blanki } \\
\text { ng }\end{array}$ & $\begin{array}{l}\text { 1. Tidak terjadi } \\
\text { Burry tebal } \\
\text { 2. Tidak terjadi } \\
\text { Burry halus } \\
\text { 3. Bagian tepi } \\
\text { part halus }\end{array}$ & $\begin{array}{l}\text { 1. Terjadi } \\
\text { Burry tebal } \\
\text { 2. Terjadi } \\
\text { Burry halus } \\
\text { 3. Tapi part } \\
\text { tajam }\end{array}$ & 3 \\
\hline $\begin{array}{l}\text { Pembu } \\
\text { atan } \\
\text { Slit }\end{array}$ & $\begin{array}{l}\text { 1. Bagian luar } \\
\text { part tidak } \\
\text { scratch } \\
\text { 2. Tidak over } \\
\text { scratch halus di } \\
\text { seluruh visual } \\
\text { part } \\
\text { 3. Tidak Scratch } \\
\text { terlalu dalam }\end{array}$ & $\begin{array}{l}\text { 1. Bagian } \\
\text { luar part } \\
\text { scratch } \\
\text { 2. Terjadi } \\
\text { over scratch } \\
\text { halus di } \\
\text { seluruh } \\
\text { visual part } \\
\text { 3. Scratch } \\
\text { terlalu dalam }\end{array}$ & 3 \\
\hline Rolling & $\begin{array}{l}\text { 1. Tidak } \\
\text { berbentuk oval } \\
\text { 2. Tidak Jigjag }\end{array}$ & $\begin{array}{l}\text { 1. Berbentuk } \\
\text { Oval } \\
\text { 2. Jigjag }\end{array}$ & 2 \\
\hline $\begin{array}{l}\text { Urifica } \\
\text { tion }\end{array}$ & $\begin{array}{l}\text { 1. Tidak tipis } \\
\text { 2. Tidak tembus }\end{array}$ & $\begin{array}{l}\text { 1. Tipis } \\
\text { 2. Tembus }\end{array}$ & 2 \\
\hline
\end{tabular}

Tahapan Measure

DPMO dan Sigma Level

Tahapan DPMO dan Sigma level reject burry dapat dilihat pada Tabel 4

Perhitungan DPMO dan Sigma Level untuk reject Burry adalah sebagai berikut

$\mathrm{DPMO}=\frac{16}{3 \times 1500} \times 1.000 .000=3556$
Nilai Sigma $=$ Normsinv $\left(\frac{1000000-3556}{1.0000000}\right) \times 1,5=4,19$

Perhitungan DPMO dan Sigma Level untuk Proses pembuatan slit adalah sebagai berikut

DPMO $=\frac{16}{3 \times 1500} x 1.000 .000=3111$

Nilai Sigma=Nomsinv $\left(\frac{1000000-3111}{1,0000000}\right) \times 1,5=4,24$

Perhitungan DPMO dan Sigma Level untuk reject penyok adalah sebagai berikut:

$$
\mathrm{DPMO}=\frac{16}{3 \times 1500} \times 1.000 .000=1000
$$

Nilai Sigma=Normsinv $\left(\frac{1000000-1000}{1.0000000}\right) \times 1,5=4,59$

Perhitungan DPMO dan Sigma Level untuk proses unfication adalah sebagai berikut

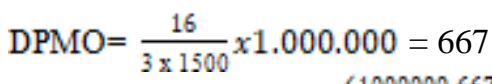

Nilai Sigma=Normsinv $\left(\frac{1000000-667}{1,000000}\right) \times 1,5=4,71$

Tabel 4 merupakan tabel keseluruhan untuk perhitungan DPMO dan Sigma Level

Tabel 4. DPMO dan Sigma Level Keseluruhan

\begin{tabular}{rlrr}
\hline No & Jenis Reject & \multicolumn{1}{c}{ DPMO } & Sigma Level \\
\hline 1 & Burry & 3341 & 4,22 \\
2 & Scratch & 2971 & 4,26 \\
3 & Penyok & 467 & 4,83 \\
4 & Tembus & 763 & 4,8 \\
& Rata-Rata & 1886 & 4,53 \\
\hline
\end{tabular}

Tabel 5. Target DPMO Dan Sigma Level Perusahaan

\begin{tabular}{|c|c|c|c|c|c|}
\hline Proses & $\begin{array}{c}\text { Jenis } \\
\text { Rejec } \\
\mathrm{t}\end{array}$ & $\begin{array}{c}\text { Total } \\
\text { Produ } \\
\text { ksi }\end{array}$ & $\begin{array}{c}\text { CTQ } \\
\text { Potens } \\
\text { ial }\end{array}$ & $\begin{array}{c}\text { DPM } \\
\text { O }\end{array}$ & $\begin{array}{c}\text { Sig } \\
\text { ma } \\
\text { Lev } \\
\text { el }\end{array}$ \\
\hline $\begin{array}{l}\text { Blankin } \\
\text { g }\end{array}$ & Burry & 1500 & 3 & 222 & 5,01 \\
\hline $\begin{array}{l}\text { Pembua } \\
\text { tan Slit }\end{array}$ & $\begin{array}{l}\text { Scrat } \\
\text { ch }\end{array}$ & 1500 & 3 & 222 & 5,01 \\
\hline Rolling & $\begin{array}{l}\text { Peny } \\
\text { ok }\end{array}$ & 1500 & 2 & 333 & 4,9 \\
\hline \multirow[t]{2}{*}{$\begin{array}{l}\text { Unficati } \\
\text { on }\end{array}$} & $\begin{array}{l}\text { Temb } \\
\text { us }\end{array}$ & 1500 & 2 & 333 & 4,9 \\
\hline & $\begin{array}{l}\text { Rata- } \\
\text { Rata }\end{array}$ & 1500 & 2,5 & 278 & 4,96 \\
\hline
\end{tabular}


Helena Sitorus, Gunawan Ferdiansyah

Submitted: 11/11/2020; Revised: 13/11/2020; Accepted: 13/11/2020; Published: 29/12/2020

\section{Control Chart}

Untuk perhitungan control chart adalah sebagai berikut:

1. Rumus mencari $\mathrm{CL}=\mathrm{CL}=\frac{696}{34160}=0,02$

2. Rumus mencari $\mathrm{UCL}=\mathrm{UCL}=0,002+3$ x $0,00364=0,03$

3. Rumus mencari $\mathrm{LCL}=\mathrm{LCL}=0,002-3$ x $0,00364=0,009$

\section{Diagram Peta Kendali}

Gambar 3 merupakan gambar peta kendali dari Reject produk

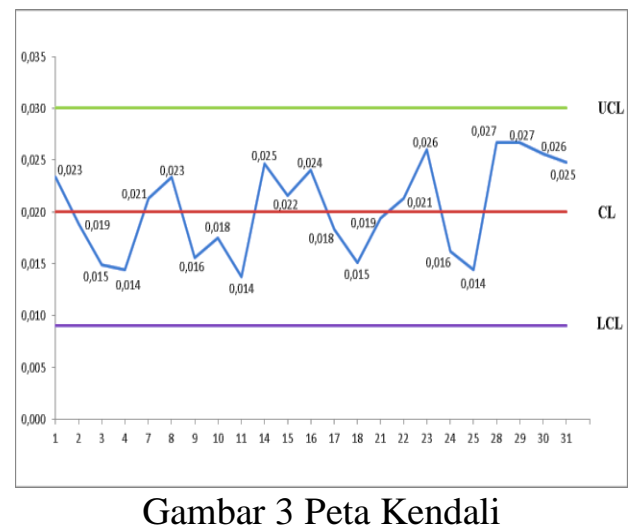

Analyze

Untuk hasil presentase reject dapat dilihat pada tabel 6

Tabel 6. Presentase Reject

\begin{tabular}{lrcc}
\hline $\begin{array}{c}\text { Jenis } \\
\text { Reject }\end{array}$ & $\begin{array}{r}\text { Jumlah } \\
\text { Defect }\end{array}$ & Presentase & $\begin{array}{c}\text { Cum } \\
\text { Presentase }\end{array}$ \\
\hline Burry & 343 & 49 & 49 \\
Scratch & 305 & 44 & 93 \\
Penyok & 32 & 5 & 98 \\
Tembus & 16 & 2 & 100 \\
Total & 696 & 100 & \\
\hline
\end{tabular}

Bahwa ditemui tingginya reject pada produk body inner K56 dengan kategori reject yaitu burry, scratch, penyok dan tembus.

\section{Diagram Pareto Jumlah Reject}

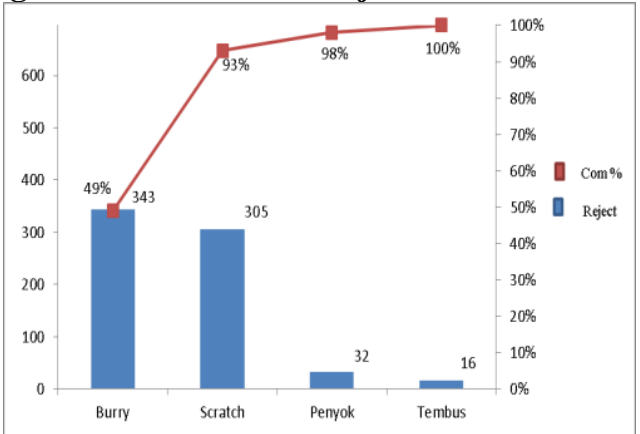

Gambar 4. Diagram Pareto Jumlah Reject

\section{Identifikasi Reject Burry Menggunakan} Cause Effect Diagram

Untuk mengetahui akar permasalahan yang sedang dihadapi pada body inner K56. Akan di buat cause effect diagram atau diagram sebab akibat untuk mengidentifikasi faktor reject burry.

Berdasarkan hasil analisis, dapat diketahui bahwa jenis kriteria reject Burry disebabkan oleh:

1. Machine = kuranngnya pengecekan dies

2. Metode = instruksi kerja tidak dilaksanakan

3. Material = man power terbatas

4. Lingkungan = area kerja sempit

5. Manusia = operator ingin cepat istirahat.

\section{Brainstorming Untuk Reject Burry}

Hasil untuk brainstorming reject burry dapat dilihat pada Tabel 7 , 
Helena Sitorus, Gunawan Ferdiansyah

Submitted: 11/11/2020; Revised: 13/11/2020; Accepted: 13/11/2020; Published: 29/12/2020

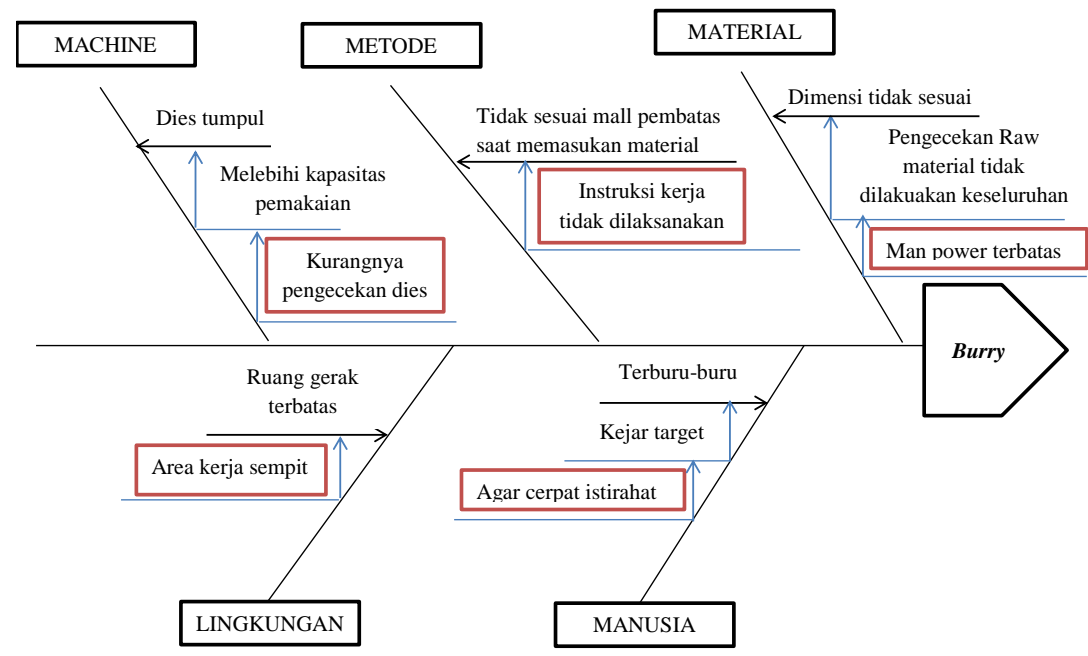

Gambar 5 Cause Effect Diagram Reject Burry

Tabel 7 Brainstorming Reject Burry

\begin{tabular}{|c|c|c|c|c|c|c|c|c|}
\hline \multirow{2}{*}{ Akar Masalah } & \multicolumn{5}{|c|}{ Pendapat dari Narasumber } & \multirow{2}{*}{$\begin{array}{l}\text { Jmlh } \\
\text { Scor }\end{array}$} & \multirow{2}{*}{ Rata-rata } & \multirow{2}{*}{ Presentase } \\
\hline & 1 & 2 & 3 & 4 & 5 & & & \\
\hline $\begin{array}{l}\text { Kurangnya } \\
\text { Pengecekan dies }\end{array}$ & 5 & 10 & 5 & 10 & 10 & 40 & 8 & 8 \\
\hline $\begin{array}{l}\text { Intruksi kerja tidak } \\
\text { dilaksanakan }\end{array}$ & 40 & 40 & 45 & 50 & 35 & 210 & 42 & 42 \\
\hline Manpower terbatas & 5 & 10 & 5 & 5 & 5 & 30 & 6 & 6 \\
\hline Area Kerja Sempit & 5 & 5 & 5 & 5 & 5 & 25 & 5 & 5 \\
\hline Agar cepat istirahat & 45 & 35 & 40 & 30 & 45 & 195 & 39 & 39 \\
\hline Total & 100 & 100 & 100 & 100 & 100 & 500 & 100 & 100 \\
\hline
\end{tabular}

\section{Diagram Pareto Dari Brainstorming Reject} Burry

Untuk mendapatkan akar masalah yang dominan maka akan digunakan diagram pareto. Dapat dilihat pada tabel 8 akar masalah instruksi kerja dengan jumlah scor 190 (38\%), dan akar masalah agar cepat istirahat jumlah scor 185 (37\%) merupakan suatu yang dominan dari ke 5 akar masalah.

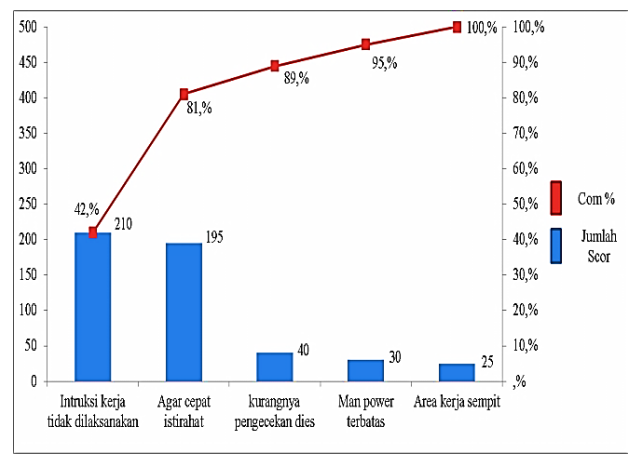

Gambar 6 Diagram Pareto
Tabel 8 Presentase Akar Masalah Burry

\begin{tabular}{|c|c|c|c|}
\hline $\begin{array}{c}\text { Akar } \\
\text { Masalah }\end{array}$ & $\begin{array}{l}\text { Jumlah } \\
\text { Scor }\end{array}$ & $\begin{array}{c}\text { Presenta } \\
\text { se }\end{array}$ & $\begin{array}{c}\text { Cum } \\
\text { Presentase }\end{array}$ \\
\hline \multicolumn{4}{|l|}{ Instruksi } \\
\hline $\begin{array}{l}\text { kerja tidak } \\
\text { dilaksanak } \\
\text { an }\end{array}$ & 210 & $42 \%$ & $42 \%$ \\
\hline $\begin{array}{l}\text { Agar cepat } \\
\text { istirahat }\end{array}$ & 195 & $39 \%$ & $81 \%$ \\
\hline \multicolumn{4}{|l|}{ Kurangny } \\
\hline $\begin{array}{c}\mathrm{a} \\
\text { pengeceka } \\
\mathrm{n} \text { dies }\end{array}$ & 40 & $8 \%$ & $89 \%$ \\
\hline $\begin{array}{c}\text { Manpower } \\
\text { terbatas }\end{array}$ & 30 & $6 \%$ & $95 \%$ \\
\hline $\begin{array}{c}\text { Area kerja } \\
\text { sempit }\end{array}$ & 25 & $5 \%$ & $100 \%$ \\
\hline Total & 500 & $100 \%$ & \\
\hline
\end{tabular}


Helena Sitorus, Gunawan Ferdiansyah

Submitted: 11/11/2020; Revised: 13/11/2020; Accepted: 13/11/2020; Published: 29/12/2020

Tabel 9 Presentase Akar Masalah

\begin{tabular}{cccc}
\hline Akar & $\begin{array}{c}\text { Jumlah } \\
\text { Masalah }\end{array}$ & $\begin{array}{c}\text { Presenta } \\
\text { se }\end{array}$ & $\begin{array}{c}\text { Cum } \\
\text { Presentase }\end{array}$ \\
\hline $\begin{array}{c}\text { Instruksi } \\
\text { kerja tidak } \\
\text { dilaksanak } \\
\text { an }\end{array}$ & 210 & $42 \%$ & $42 \%$ \\
$\begin{array}{c}\text { Agar cepat } \\
\text { istirahat } \\
\text { Kurangny } \\
\text { a }\end{array}$ & 195 & $39 \%$ & $81 \%$ \\
$\begin{array}{c}\text { pengeceka } \\
\text { n dies }\end{array}$ & 40 & $8 \%$ & $89 \%$ \\
$\begin{array}{c}\text { Manpower } \\
\text { terbatas }\end{array}$ & 30 & $6 \%$ & $95 \%$ \\
Area kerja \\
sempit \\
Total & 25 & $5 \%$ & $100 \%$ \\
\hline
\end{tabular}

Identifikasi Reject Scratch Menggunakan Cause Effect Diagram

Berdasarkan hasil analisis, dapat diketahui bahwa jenis kriteria reject Scratch disebabkan oleh:
1. Machine
$=$ kurangnya kontrol
collent
2. Metode = kurangnya skill man
power
3. Material = dies mesin stamping
kotor
4. Lingkungan $=$ kurang aktivitas kebersihan
5. Manusia = operator mengejar waktu istirahat yang banyak

Brainstorming untuk rejecr Scratch dapat dilihat pada Tabel 15

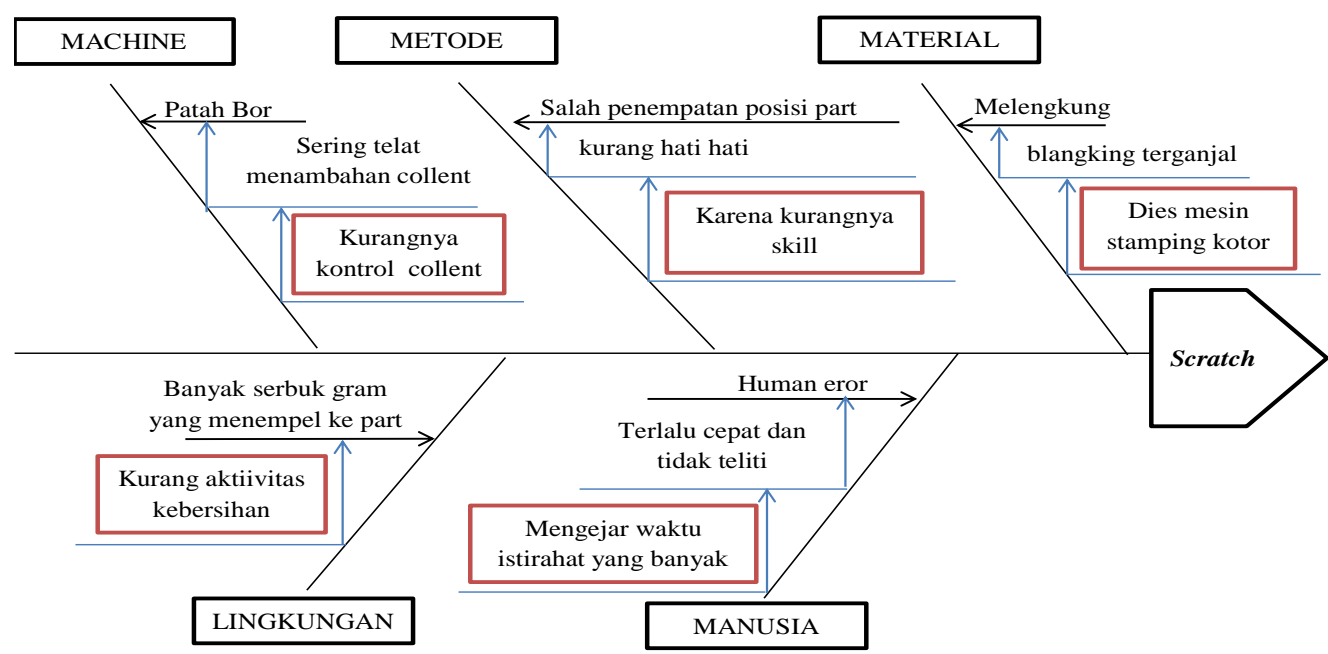

Gambar 7 Cause Effect Diagram Reject Scratch

Tabel 10. Brainstorming Reject Scratch

\begin{tabular}{lcccccccc}
\hline \multicolumn{1}{c}{ Akar Masalah } & \multicolumn{9}{c}{ Pendapat dari Narasumber } & Jmlh & \multirow{2}{*}{ Rata-rata } & \multirow{2}{*}{ Presentase } \\
\hline $\begin{array}{l}\text { Instruksi kerja tidak } \\
\text { dilaksanakan }\end{array}$ & 5 & 10 & 5 & 5 & 5 & 25 & 5 & 5 \\
$\begin{array}{l}\text { Agar cepat istirahat } \\
\text { Kurangnya }\end{array}$ & 45 & 55 & 35 & 50 & 45 & 230 & 46 & 46 \\
pengecekan dies & 5 & 10 & 10 & 5 & 10 & 35 & 7 & 7 \\
$\begin{array}{l}\text { Manpower terbatas } \\
\text { Area kerja sempit }\end{array}$ & 5 & 5 & 10 & 10 & 10 & 40 & 8 & 8 \\
Total & 100 & 110 & 40 & 30 & 45 & 170 & 34 & 34 \\
\hline
\end{tabular}


Helena Sitorus, Gunawan Ferdiansyah

Submitted: 11/11/2020; Revised: 13/11/2020; Accepted: 13/11/2020; Published: 29/12/2020

\section{Diagram Pareto Dari Brainstorming Reject Scratch}

Diagram Pareto dari Brainstorming Reject Scracth dapat dilihat pada Gambar 8. Sedangkan Tabel 11 merupakan hasil dari pencarian akar masalah pada Reject Scratch

Untuk mendapatkan akar masalah yang dominan maka digunakan diagram pareto pada gambar 8 diatas untuk mengetahui akar masalah yang terbesar sampai yang terkecil. Jika dilihat pada tabel 11 akar masalah instruksi kerja dengan jumlah scor 205 (41\%), dan akar masalah agar cepat istirahat jumlah scor 170 (34\%) merupakan suatu yang dominan dari ke 5 akar masalah.

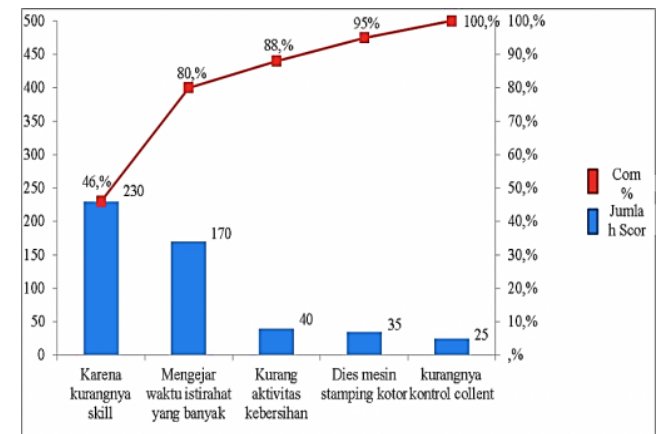

Gambar 8 Pareto dari Brainstorming Reject Scratch

Tabel 11 Presentase Akar Masalah

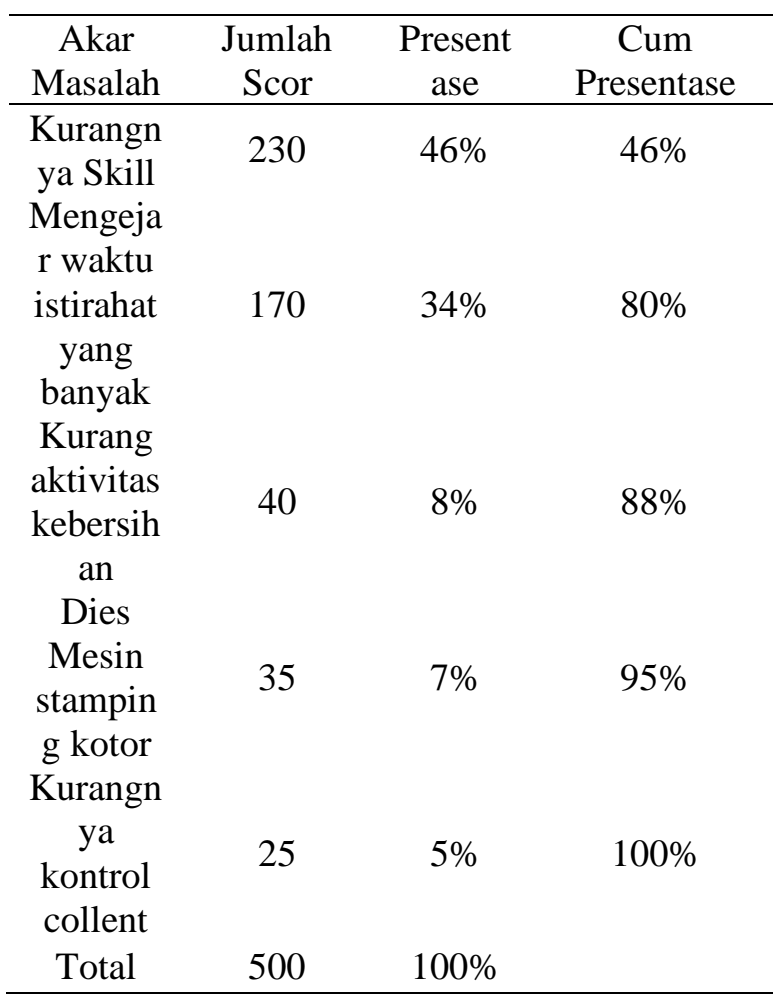

\section{Improvement}

Tindakan Perbaikan Dengan 5W1H Reject Burry

Metode dengan akar masalah instruksi kerja tidak dilaksanakan.

Tabel 12 Penjelasan Metode 5W1H Reject Burry

\begin{tabular}{cl}
\hline ITEM & \multicolumn{3}{c}{ PENJELASAN } \\
\hline What & $\begin{array}{l}\text { Tidak sesuai mal pembatas saat } \\
\text { memasukan material }\end{array}$ \\
\hline Where & Machine stamping \\
\hline When & $\begin{array}{l}\text { Saat man power melakukan proses } \\
\text { produksi pada machine stamping } \\
\text { mengabaikan instruksi kerja }\end{array}$ \\
\hline Why & Instruksi kerja tidak di laksanakan \\
\hline Who & $\begin{array}{l}\text { Man power produksi yang mengoprasikan } \\
\text { machine stamping }\end{array}$ \\
\hline Menjalankan intruksi kerja, lebih teliti \\
saat memasukan material kedalam dies \\
pastikan pas dengan mal pembatas, dan \\
selalu membersihkan bagian dalam dies \\
agar tidak ada sisa potongan scrap
\end{tabular}

Manusia dengan akar masalah agar cepat istirahat.

Tabel 13 Penjelasan Manusia 5W1H Reject Burry

\begin{tabular}{cl}
\hline ITEM & \multicolumn{1}{c}{ PENJELASAN } \\
\hline What & Terburu-buru \\
\hline Where & $\begin{array}{l}\text { Proses blangking pada machine } \\
\text { stamping }\end{array}$ \\
\hline When & Saat memasukan material kedalam dies \\
\hline Why & Agar cepat istirahat \\
\hline Who & Man power machine stamping \\
\hline How & $\begin{array}{l}\text { Checkman melakukan pengawasan } \\
\text { terhadap man power saat melakukan } \\
\text { proses produksi agar bekerja sesuai cycle } \\
\text { time yang telah di tetapkan dalam proses } \\
\text { agar lebih efisien dalam menjaga kualitas }\end{array}$ \\
\hline
\end{tabular}

\section{Tindakan Perbaikan \& Pencegahan dengan 5W1H Reject Scratch}

Metode dengan akar masalah menitik beratkan skill man power 
Helena Sitorus, Gunawan Ferdiansyah

Submitted: 11/11/2020; Revised: 13/11/2020; Accepted: 13/11/2020; Published: 29/12/2020

Tabel 14 Penjelasan Metode 5W1H Reject Scratch

\begin{tabular}{cl}
\hline ITEM & \multicolumn{2}{c}{ PENJELASAN } \\
\hline What & $\begin{array}{l}\text { Salah saat melakukan penempatan part pada } \\
\text { stoper machine notching saat menjalankan } \\
\text { proses }\end{array}$ \\
\hline Where & $\begin{array}{l}\text { Pada saat proses pembuatan slit di machine } \\
\text { notching }\end{array}$ \\
\hline When & $\begin{array}{l}\text { Disaat penenmpatan part tidak sesuai dengan } \\
\text { stoper }\end{array}$ \\
\hline Why & Karena kurangnya skill \\
\hline Who & $\begin{array}{l}\text { Man power produksi yang mengoprasikan } \\
\text { machine notching untuk proses pembuatan slit }\end{array}$ \\
\hline How & $\begin{array}{l}\text { Melakukan pelatihan mendalam untuk man } \\
\text { power, memberikan warning instruksi } \\
\text { penempatan part saat menjalankan proses, dan } \\
\text { di himbau agar lebih teliti }\end{array}$
\end{tabular}

Manusia dengan akar masalah mengejar waktu istirahat yang banyak

Tabel 15 Penjelasan Manusia 5W1H Reject

\begin{tabular}{|c|c|}
\hline \multicolumn{2}{|r|}{ Scratch } \\
\hline ITEM & PENJELASAN \\
\hline What & $\begin{array}{l}\text { Terjadinya human eror karena pekerjaan } \\
\text { yang dilakukan terlalu cepat dan tidak teliti }\end{array}$ \\
\hline Where & Proses pembuatan slit pada machine notching \\
\hline When & \\
\hline & $\begin{array}{l}\text { Saat melakukan proses pembuatan slit salah } \\
\text { menempatkan posisi part terbalik atau miring }\end{array}$ \\
\hline Why & Mengejar waktu istirahat yang banyak \\
\hline Who & Man power machine notching \\
\hline How & $\begin{array}{l}\text { Menetapkan aturan waktu saat bekerja } \\
\text { menhimbau agar lebih teliti, dan jika ada } \\
\text { waktu lenggang lakukan aktivitas kebersihan } \\
\text { pada mesin agar waktu tidak terbuang } \\
\text { percuma }\end{array}$ \\
\hline
\end{tabular}

Nilai DPMO dan Sigma Level Sebelum dan Sesudah

Berdasarkan hasil penerapan metode six sigma diperoleh nilai sigma dan nilai DPMO. Nilai perbaikan sebelum dan sesudah penerapan metode six sigma dapat dilihat pada tabel 16.

Tabel 16 Keseluruhan DPMO dan Sigma Level sebelum dan sesudah perbaikan

\begin{tabular}{lrrrr}
\hline \multirow{2}{*}{$\begin{array}{c}\text { Jenis } \\
\text { Reject }\end{array}$} & \multicolumn{2}{c}{ Sebelum } & \multicolumn{2}{c}{ Sesudah } \\
DPMO & $\begin{array}{c}\text { Sigma } \\
\text { Level }\end{array}$ & DPMO & $\begin{array}{c}\text { Sigma } \\
\text { Level }\end{array}$ \\
\hline Burry & 3341 & 4,22 & 361 & 4,91 \\
Scratch & 2971 & 4,26 & 371 & 4,9 \\
Rata-rata & 3156 & 4,24 & 366 & 4,905 \\
\hline
\end{tabular}

Control

Berikut usulan perbaikan yang diusulkan oleh peneliti:

1 Pengawasan pada pekerja yang lalai, terburu-buru dan tidak fokus.

2 Pelatihan terjadwal kepada man power selama 1 atau 2 bulan sekali untuk. meningkatkan skill man power.

3 Memberikan arahan terhadap man power untuk selalu menjaga efisiensi waktu saat bekerja agar tidak membuang waktu dengan sia-sia.

4 Pengawasan pada mesin secara berkala untuk menghindari troubleshoot mesin secara otomatis atau mengoperasikan mesin sesuai dengan kemampuan mesin.

5 Melakukan selalu check part raw material maupun part next prosess secara berkala menggunakan from check agar bisa mengontrol dan mengendalikan kualitas agar tetap dalam batas standar yang ditetapkan perusahaan

6 Membuat tempat alokasi material sementara agar tidak melakukan penundaan material pada area kerja yang berakibat mengganggu ruang gerak man power yang menyebabkan area kerja sempit. 
Helena Sitorus, Gunawan Ferdiansyah

Submitted: 11/11/2020; Revised: 13/11/2020; Accepted: 13/11/2020; Published: 29/12/2020

Tabel 17 Pelaksanaan PIC Pengawasan Reject Burry

\begin{tabular}{|c|c|c|c|}
\hline How & PIC & Dokumen & Keterangan \\
\hline $\begin{array}{l}\text { Instruksi kerja tidak } \\
\text { dilaksanakan }\end{array}$ & $\begin{array}{l}\text { Check } \\
\text { Manpower }\end{array}$ & $\begin{array}{l}\text { Laporan } \\
\text { Pelaksanaan }\end{array}$ & $\begin{array}{l}\text { Wajib memberitahu manpower untuk } \\
\text { mengisi sheet SOP saat melakukan } \\
\text { produksi }\end{array}$ \\
\hline Agar cepat istirahat & $\begin{array}{l}\text { Check } \\
\text { Manpower }\end{array}$ & $\begin{array}{l}\text { Warning break } \\
\text { tepat waktu }\end{array}$ & $\begin{array}{l}\text { Memberikan peringatan saat jam } \\
\text { istirahat dengan bel yang bertujuan agar } \\
\text { waktu istirahat lebih teratur }\end{array}$ \\
\hline $\begin{array}{l}\text { Kurangnya } \\
\text { pengecekan dies }\end{array}$ & DMD & $\begin{array}{l}\text { Laporan } \\
\text { maintenance } \\
\text { dies }\end{array}$ & $\begin{array}{l}\text { Mengisi laporan rutin terhadap kondisi } \\
\text { dies bertujuan untuk mengetahui masa } \\
\text { pakai dies }\end{array}$ \\
\hline Manpower terbatas & HRD & Recruitment & $\begin{array}{l}\text { Memberikan saran agar ada } \\
\text { penambahan operato pada divisi } \\
\text { penerimaan barang sebagai checker }\end{array}$ \\
\hline Area kerja sempit & GM & $\begin{array}{l}\text { Laporan fasilitas } \\
\text { area kerja }\end{array}$ & $\begin{array}{l}\text { Membuat laporan jika terdapat kendala } \\
\text { di area kerja seperti penempatan } \\
\text { materian alokasi sementara }\end{array}$ \\
\hline
\end{tabular}

Tabel 18 Pelaksanaan PIC Pengawasan Reject Scratch

\begin{tabular}{llll}
\hline \multicolumn{1}{c}{ How } & \multicolumn{1}{c}{ PIC } & \multicolumn{1}{c}{ Dokumen } & \multicolumn{1}{c}{ Keterangan } \\
\hline $\begin{array}{l}\text { Menitikberatkan pada } \\
\text { skill manpower }\end{array}$ & $\begin{array}{l}\text { Check } \\
\text { Manpower }\end{array}$ & $\begin{array}{l}\text { Laporan } \\
\text { pelatihan }\end{array}$ & $\begin{array}{l}\text { Melakukan pelatihan terjadwal kepada } \\
\text { manpower untuk menumbuhkan skill } \\
\text { tersendiri }\end{array}$ \\
$\begin{array}{l}\text { Mengejar waktu } \\
\text { istirahat yang banyak }\end{array}$ & $\begin{array}{l}\text { Check } \\
\text { Manpower }\end{array}$ & $\begin{array}{l}\text { Attention fast } \\
\text { work }\end{array}$ & $\begin{array}{l}\text { Memberikan peringatan kepada } \\
\text { manpower agar selalu membuat } \\
\text { efisiensi waktu kosong dan sper waktu } \\
\text { istirahat }\end{array}$ \\
$\begin{array}{l}\text { Kurang aktivitas } \\
\text { kebersihan }\end{array}$ & DMD & Laporan 5K2S & $\begin{array}{l}\text { Mengisi laporan rutin kebersihan line } \\
\text { maupun mesin setelah selesai produksi }\end{array}$ \\
$\begin{array}{l}\text { Dies Mesin stamping } \\
\text { kotor }\end{array}$ & HRD & Laporan 5K2S & $\begin{array}{l}\text { Mengisi laporan pembersihan dies } \\
\text { dengan timeout yang sudah ditetapkan } \\
\text { guna efisiensi waktu }\end{array}$ \\
$\begin{array}{l}\text { Kurangnya kontrol } \\
\text { collent }\end{array}$ & GM & Laporan fasilitas \\
mesin & $\begin{array}{l}\text { Membuat laporan pengisian collent } \\
\text { dengan terjadwal dan mengisi sheet } \\
\text { untuk mengontrol }\end{array}$ \\
\hline
\end{tabular}

\section{KESIMPULAN DAN SARAN KESIMPULAN}

Berdasarkan hasil pengolahan dan analisis data dapat disimpulkan akar masalah dominan reject body inner K56, yaitu Reject burry dengan instruksi kerja saat memasukan material agar sesuai mal pembatas tidak dilaksnakan (Faktor 149 metode), Keinginan untuk cepat istirahat sehingga terburu-buru untuk mencapai target. (Faktor manusia). Reject scratch; kurangnya skill untuk menempatkan posisi part pada stoper, Mengejar waktu istirahat yang banyak sehingga terburu-buru. Usulan perbaikan kualitas untuk proses pembuatan body inner k56. Usulan perbaikan reject burry; 
Helena Sitorus, Gunawan Ferdiansyah

Submitted: 11/11/2020; Revised: 13/11/2020; Accepted: 13/11/2020; Published: 29/12/2020

Menjalankan intruksi kerja, lebih teliti saat memasukan material kedalam dies pstikan pas dengan mal pembatas, dan selalu membersihkan bagian dalam dies agar tidak ada sisa potongan scrap. (How, untuk metode), Checkman melakukan pengawasan terhadap man power saat melakukan proses produksi, agar bekerja sesuai cycle time yang telah ditetapkan dalam proses agar kebih efisien dalam menjaga kualitas. (How, untuk manusia). Usulan perbaikan reject scratch; Melakukan pelatihan mendalam untuk man power, memberikan warning intruksi penempatan part saat menjalankan proses, dan di himbau agar lebih teliti. (How, untuk metode), Menetapkan aturan waktu saat bekerja, menghimbau agar tidak terlalu cepat, dan jika ada waktu lenggang lakukan aktivitas kebersihan pada mesin agar waktu tidak terbuang percuma. (How, untuk manusia).

\section{DAFTAR PUSTAKA}

Ardiansyah, F (2014). Pengendalian Cacat Produk Dengan Pendekatan Six Sigma. Jurnal Dinamika Teknik. Vol 8 No 1. Januari 2014.

Assauri S. (2014). Manajemen Pemasaran Raja Grafindo Persada : Jakarta.

Bakhtiar, S. (2013). Analisa Pengendalian Kualitas Dengan Menggunakan Metode Statistical Quality Control (SQC), Jurnal Malikussaleh Industrial Engineering, Vol 2 No. 1, Mei 2013.

Bilsel, R. (2012). Ishikawa Cause and Effect Diagrams Using Capture Recapture Techniques, Jurnal Quality Technology Quantitative Management (QTQM), Vol 9 No. 2, Juni 2012.

Gaspersz, V. (2011). Lean Six Sigma for Manufacturing and Service Industries. Bogor : Vinchristo Publication.

Ilyas, R. (2015). Ekstraksi Informasi 5W1H Jurnal Cybermatika, Vol 3 No. 1, Juni 2015.

Indri, C. (2012). Pengendalian Kualitas Produk Cacat Dengan Pendekatan Kaizen Dan Analisis Masalah Dengan Seven Tools Jurnal Teknik Industri Institut Sains \& Teknologi AKPRIND Yogyakarta, Vol 3 No. 3, November 2012.

Isma, P.B. (2012). Penerapan Metode Six sigma Untuk Menurunkan Kecacatan Produk Jurnal Online Institut Teknologi Nasional, Vol 4 No. 1, Juli 2012.
Muhaemin, A. (2012). Analisis Pengendalian Kualitas Produk Dengan Metode Six Sigma pada Harian Tribun Timur. Skripsi. Makassar : Universitas Hasanuddin.

Nastiti, H. (2014). Analisis pengendalian kualitas produk dengan metode statistical quality control (Studi Kasus: pada PT X Depok), Jurnal Sustainable Competitive Advantage. Vol 2, Januari 2014

Primastuti, N.B. (2014). Pengontrolan Kualitas Produk Menggunakan Metode Diagram Kontrol Multivariat np (Mnp) dalam Usaha peningkatan Kualitas. Jurnal Gaussian, Vol 3 No. 1, Januari 2014.

Purwanto, (2010). Metodologi Penelitian Kuantitatif untuk Psikologi dan Pendidikan. Yogyakarta: Pustaka Pelajar.

Roestiyah N.K. (2012). Strategi Belajar Mengajar Model Pembelajaran Brainstorming. Jurnal Ide Dan Inovasi, Vol 3 Mei 2012.

Sunyoto, D. (2014) Dasar-Dasar Manajemen Pemasaran (Konsep,Strategi, dan Kasus) Jurnal CAPS (Center For Academic Fublishing Service), Vol 1 Maret 2014.

Susetyo J, dkk. (2011). Aplikasi Six Sigma DMAIC dan Kaizen sebaai Metode Pengendalian Dan Perbaikan Kualitas Produk. Jurnal Teknologi, Vol 4, No. 1, Juni 2011 